\title{
Multi Objective Optimal Reactive Power Flow Based STATCOM Using Three Variant of PSO
}

\author{
N. Mancer, B. Mahdad", K. Srairi \\ Department of Electrical Engineering, University of Biskra, Biskra (07000), Algeria
}

\begin{abstract}
This paper proposes, an efficient variant of particle swarm optimization (PSO) to solve the multi-objective optimal reactive power flow (ORPF) based flexible AC transmission system (FACTS) using multi STATCOM Controllers by adjusting dynamically their parameters setting. Two objectives function are considered (power loss and voltage deviation) to validate the robustness of the proposed approach. The performance of the proposed variant based PSO approach has been tested on the standard test system IEEE 30-bus; simulation results compared to the standard PSO confirm the effectiveness of the proposed variant to solving the multi-objective reactive power considering multi STATCOM Controllers.
\end{abstract}

Keywords Reactive Power Optimization, Particle Swarm Optimization (PSO), FACTS, Multi Objective, STATCOM

\section{Introduction}

The optimal reactive power flow (ORPF) is one of important optimization in power system. The reactive power optimization problem is multi-variable, non differentiable and non-linear[1], furthermore it involves controlling of continuous and discrete variable. The objective of ORPF problem is optimization a certain variables to minimize an objective function for example the active power loss, and voltage deviation by adjustment of the voltage level of the generation, switched capacitor shunt and the tab of the transformer, while satisfying the physical and operational constraint equality and constraint inequality.

Many techniques ranging from conventional mathematical methods have been proposed to deal with reactive power dispatch, such as traditional method including linear programming[2] non- linear programming[3]; quadratic programming[4] and interior point methods[5], this method can not ensure the acquirement of the whole optimization.

To overcome the drawbacks of the conventional methods, a variety of global optimization[6] techniques have been successfully used to solve the ORPF problem, these optimization techniques including, genetic algorithm (GA)[7], particle swarm optimization (PSO)[8], Tabu search (TS)[9], differential evolution (DE)[10,11], and they are now considered as a promising alternative to solve this kind of problem.

The classical particle swarm optimization (PSO) first in-

* Corresponding author:

bemahdad@mselab.org (B. Mahdad)

Published online at http://journal.sapub.org/ijee

Copyright (C) 2012 Scientific \& Academic Publishing. All Rights Reserved troduced by Kennedy and Eberhart 1995[12], this method applied with success to solve the reactive power planning, PSO developed through simulation of a simplified social system, and has been found to be robust and flexible in solving optimization problem, because this technique can generate a high-quality solution within shorter calculation time and stable convergence characteristic than other stochastic methods.

Recently the new technology known as FACTS introduction to system electricity to improve the performance of the large practical electrical network. The concept of Flexible AC Transmission Systems (FACTS) was first defined by N.G. Hingorani, in 1988[13]. A Flexible Alternating Current Transmission System (FACTS) is defined by the IEEE as "a power electronic based system and other static equipment that provide control of one or more AC transmission system parameters to enhance controllability and increase power transfer capability"[14]. FACTS-devices can be utilized to increase the transmission capacity, improve the stability and dynamic behavior or ensure better power quality in modern power systems in comparison to conventional devices like switched compensation. The FACTS controllers based on voltage source converter (VSC) have several and advantages over the variable impedance type, for example, a STATCOM $[15,16]$ is much more compact than a SVC[17] for similar rating and is technically superior. It can supply required reactive current even at low values of the bus voltage.

In this work a three variant of PSO are proposed to solve the multi objective optimal reactive power planning based multi STATCOM Controllers, the basic idea behind these variants related in a flexible control of swarm position (velocity variation) coordinated with dynamic control of shunt FACTS devices based multi STATCOM Controllers. 


\section{Multi Objective ORPF Formulation}

The multi objective ORPF is to optimize the settings of control variables in terms of one or more objective functions while satisfying several equality and inequality constraints. In multi objective ORPF we have to optimize two or more objective functions simultaneously. The problem can be formulated as:

$$
\begin{gathered}
\text { Minimize } J_{i}(x, u) \quad i=1, \ldots, N_{o b j} \\
\text { Subject to }: g(x, u)=0 \\
h(x, u)=0
\end{gathered}
$$

Where $J_{i}$ is the ith objective function, and $N_{o b j}$ is the number of objectives. $\mathrm{G}$ is the equality constraints, $\mathrm{h}$ is the system operation constraints. The main objective of this work is to optimize two competing objective functions, power loss and voltage deviation, while satisfying several equality and inequality constraints. The function can be written in the following $[18,15,16]$ :

$$
\begin{gathered}
F=\min ((1-U) * f 1+U * f 2) \\
U \in[0,1]
\end{gathered}
$$

Where: $f_{1}, f_{2}$ are the two objective functions to be optimized simultaneously.

\subsection{Objectives Functions}

a. Power loss

The first objective of the ORPF problem is to minimize the active power loss in the transmission network, which is defined as follows:

$$
\begin{aligned}
f_{1} & =\min P_{\text {loss }}\left(x_{1}, x_{2}\right) \\
& =\sum_{k=1}^{n l} g_{k}\left[V_{i}^{2}+V_{j}^{2}-2 * V_{i} V_{j}\right]
\end{aligned}
$$

where $\mathrm{P}_{\text {loss }}\left(x_{1}, x_{2}\right)$ is the active power loss, $x_{1}$ is the control variable vector [VG Q STATCOM], VG is the generator voltage (continuous), Q STATCOM is the shunt capacitor/inductor, $x_{2}$ is the dependent variable vector [VL, QG], $\mathrm{VL}$ is the load-bus voltage, $\mathrm{QG}$ is the generator reactive power, $g_{k}$ is the conductance of branch between bus $i$, and $j, V_{i}, V_{j}$ is the voltage at bus $\mathrm{i}-\mathrm{j}$.

b. Voltage Deviation

The second objective function consists in minimizing the voltage deviation in the load bus, may expressed by the following equation:

$$
f_{2}=\min V D=\sum_{i=1}^{n p q}\left|V_{i}-V_{r e f}\right|
$$

$\mathrm{npq}$ : is the set number of load-bus.

Vref : is the set voltage reference (1.0 p.u).

\subsection{Constraints}

The equality constraints represent the power flow equations

$$
\begin{gathered}
P_{i}-V_{i} \sum_{j}^{N b} V_{j}\left(G_{i j} \cos \theta_{i j}+B_{i j} \sin \theta_{i j}\right)=0 \\
Q_{i}-V_{i} \sum_{j=1}^{N b} V_{j}\left(G_{i j} \sin \theta_{i j}-B_{i j} \cos \theta_{i j}\right)=0
\end{gathered}
$$

$\mathrm{i}=1: \mathrm{Nb}-1$

where $V j$ is the voltage at bus $\mathrm{j}, \theta i j$ is the voltage angle difference between bus $i$ and $j$, Gij is the conductance between bus $i$ and bus $j, B i j$ is the susceptance between bus $\mathrm{i}$ and $\mathrm{j}, \mathrm{Nb}$ is the set of numbers of buses, $\mathrm{N}_{\mathrm{pq}}$ is the set of numbers of total buses load bus,

The inequality constraints of the system consist of the upper and lower limits of active power generation of slack bus, load bus voltage, control variable limit, reactive power generation and the Shunt FACTS parameters which are described by:

$$
\begin{gathered}
P_{g, \text { slack }}^{\min } \leq P_{g, \text { slack }} \leq P_{g, \text { slack }}^{\max } \\
V_{L, i}^{\min } \leq V_{L, i} \leq V_{L, i}^{\max } \\
V_{g, i}^{\min } \leq V_{g, i} \leq V_{g, i}^{\max } \\
Q_{g, i}^{\min } \leq Q_{g, i} \leq Q_{g, i}^{\max } \\
Q_{\text {STATCOM }}^{\min } \leq Q_{\text {STATCOM }} \leq Q_{\text {STATCOM }}^{\max }
\end{gathered}
$$

\section{PSO Strategy}

Since the introduction of PSO method, a number of different PSO strategies are being applied by researchers for solving the ORPF, and other complex problem.

PSO is a based modern heuristic search method motivated from the simulation of the behaviour of social systems such as fish schooling and birds flocking[12]. The motivation behind this concept is to well balance the exploration and exploitation capability for attaining better convergence to the optimal solution. The PSO beginning, a population of particles is initialized with random positions marked by vectors $x i$ and random velocities $v i$, population of such particles is called a "swarm". The particles update their positions using their own experience and the experience of their neighbours. The update mode is termed as the velocity of particles[19].

The modified velocity and position of each particle can be calculated using the current velocity and the distance from $\mathrm{Pi}$ to $P g$ as shown in the following formulas general:

$$
\left\{\begin{array}{c}
V(t+1)=w^{*} V(t)+c_{1} \text { rand }_{1} *\left(\text { Pbest }_{i}-X(t)\right) \\
\quad+c_{2} \text { rand }_{2} *\left(\text { Gbest }_{i}-X(t)\right) \\
X(t+1)=X(t)+V(t+1)
\end{array}\right.
$$

where $V(t)$ is the current velocity, $V(t+1)$ is the velocity (modified velocity) rand 1 and rand 2 are the random numbers between 0 and 1, Pi is the best value found by particle $i$, $P g$ is the best particle found in the group, $X(t)$ is the current position $X(t+1)$ is the current position (modified searching point), Here $\mathrm{w}$ is the inertia weight parameter, $\mathrm{C}$ is constriction factor, c1; c2 are cognitive and social coefficients. A large inertia weight helps in good global search while a smaller value facilitates local exploration.

An inertia weight in the PSO algorithm was introduced in 1998 , in order to provide better control exploration, the practice is to use larger inertia weight factor during initial exploration and gradual reduction of its value as the search proceeds in further iterations. The concept of time varying inertial weight was introduced in[20] and is given by: 


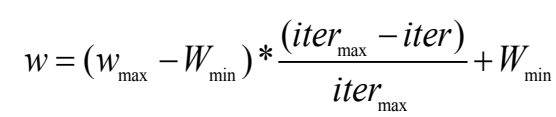

where iter is the current iteration number while iter $_{\max }$ is the maximum number of iterations. Usually the value of $\mathrm{w}$ is the inertia weight factor varied between 0.9 and 0.4 . Constant $\mathrm{c} 1$ pulls the particles towards local best position whereas $\mathrm{c} 2$ pulls it towards the global best position. The constriction factor [21] is used to improve the convergence of PSO algorithm and is given by:

$$
\begin{gathered}
\left\{\begin{aligned}
V(t+1)=C(V(t) & +c_{1} \text { rand }_{1} *\left(\text { Pbest }_{i}-X(t)\right) \\
& \left.+c_{2} \text { rand }_{2} *\left(\text { Gbest }_{i}-X(t)\right)\right) \\
X(t+1)= & X(t)+V(t+1)
\end{aligned}\right. \\
C=\frac{2}{\left|2-\varphi-\sqrt{\varphi^{2}-4 \varphi}\right|}
\end{gathered}
$$

Where; $4,1 \leq \mathrm{c} \leq 4,2$

As $(\varphi)$ increases, the factor $\mathrm{C}$ decreases and convergence becomes slower because population diversity is reduced. In the first and second variant of PSO, these values are kept constant. However, in three variant, the velocity, $V(t+1)$ is modified by a factor known as constriction factor, $C$ such that $(V(t+1)=\mathrm{C} V(t))$. This modification increases the performance of modified PSO. The factor, $K$ is selected between $(0,1)$. The constriction factor can be taken as fixed value or varied randomly. Typically, if $\varphi=4.1$, then the constriction factor $\mathrm{C}=0.729$ and $\mathrm{C} 1=\mathrm{C} 2=2.05$. Table 1 describes and resumed the parameter of the three proposed variant of PSO.

Table 1. Parameters of the three PSO Variants

\begin{tabular}{|c|c|c|c|}
\hline \multirow{2}{*}{} & \multicolumn{3}{|c|}{ The variant of PSO algorithm } \\
\cline { 2 - 4 } & PSO1 & PSO2 & PSO3 \\
\hline Max No. of iterations & 100 & 100 & 100 \\
\hline Swarm size & $\mathbf{2 0}$ & $\mathbf{2 0}$ & $\mathbf{2 0}$ \\
\hline Inertia weight factor, $w$ & 1 & $0.9-0.4$ & - \\
\hline \multirow{2}{*}{ Weighting factors c1,c2 } & $\mathrm{C} 1=1$, & $\mathrm{C} 1=1$, & \multirow{2}{*}{$\mathrm{C} 1=2.05,2=2.05$} \\
& $\mathrm{C} 2=1$ & $\mathrm{C} 2=1$ & 0.729 \\
\hline C coefficient & - & - & \multicolumn{3}{|c}{} \\
\hline
\end{tabular}

The flow chart of the proposed algorithm based STAT$\mathrm{COM}$ is described in Figure 1:

\section{Modeling of STATCOM with Power Flow}

STATCOM is a second generation of FACTS device used for shunt reactive power compensation. According to the IEEE, STATCOM system is a static synchronous generator operated as a static compensator connected in parallel whose output current (inductive or capacitive) can be controlled independently of the AC system voltage [15]. The bus at which the STATCOM is connected is represented as a PV bus, this dispositive can be generated or absorbed reactive power would reach to the maximum limit. Figure.2.a shows the basic configuration of STATCOM [16].

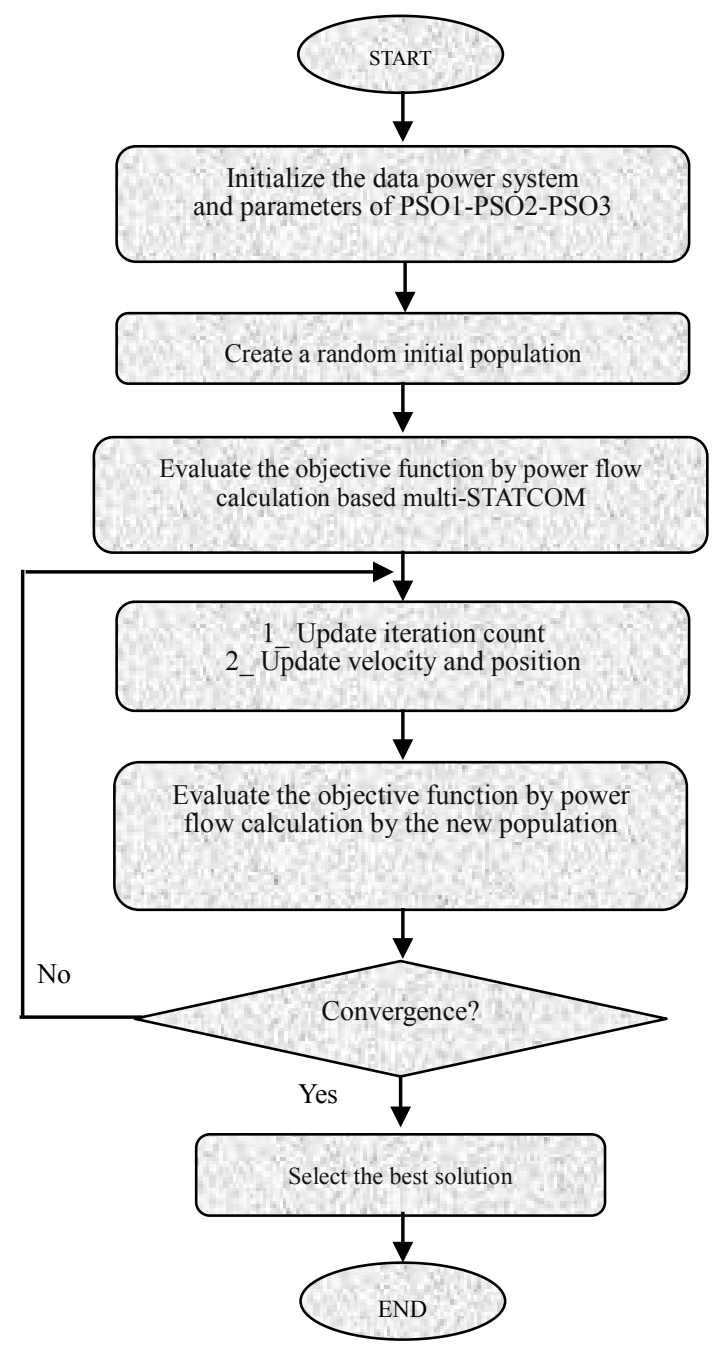

Figure 1. Flow Chart of the proposed algorithm based three PSO variants

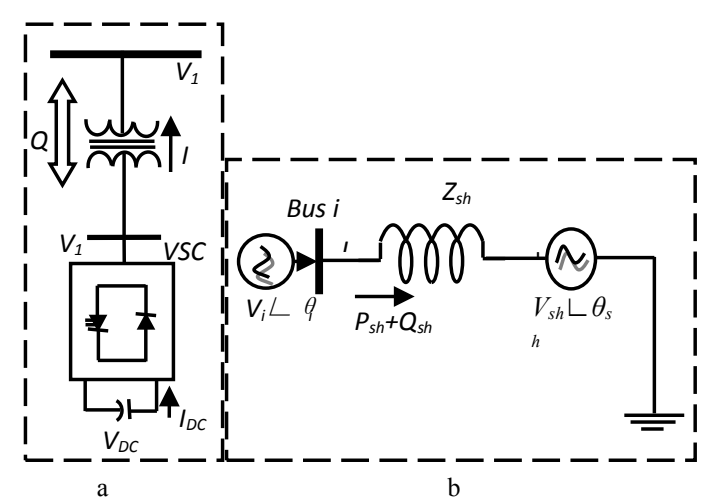

Figure 2. a) Basic configuration of STATCOM. B) STATCOM equivalent circuit

The steady state control characteristics of a STACOM is shown in Fig 3, the losses in the STATCOM are neglected and $\mathrm{I}_{\text {STATCOM }}$ is assumed be purely reactive. as in the case of a SVC the negative current indicates capacitive operation while positive current indicate inductive operation the reference voltage corresponds to zero current output the STATCOM much more compact than a SVC, it can be 
generated reactive current with low values of the bud voltage[14].

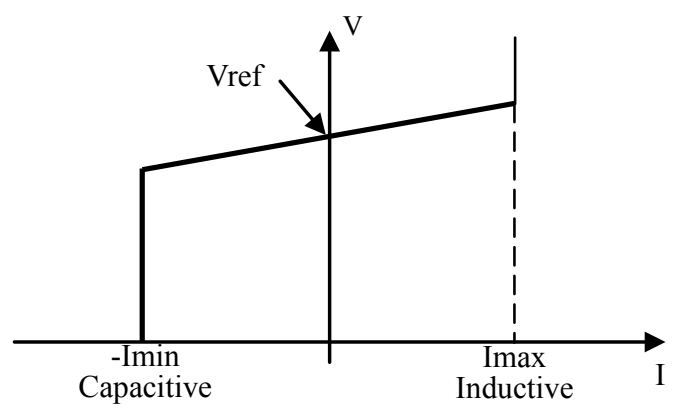

Figure 3. Steady state control characteristics of a STACOM

A. Power Flow Equation with STATCOM

An alternative way to model the STATCOM in a Newton-Raphson power flow algorithm is described in this section. It is a simple and efficient model based on the use of a variable voltage source, which adjusts automatically in order to achieve a specified voltage magnitude. In this case, the nodal at which the STATCOM is connected is a controlled node where the nodal voltage magnitude and the nodal active and reactive powers are specified while the source voltage magnitude is handled as a state variable. The STATCOM equivalent circuit shown in Fig 2.b[16].

The power transmission line between two bus system can be represented by:

The active power transmitted

$$
P=\frac{V_{i^{*}} V_{s h}}{X} \sin \left(\delta_{i}-\delta_{s h}\right)
$$

The reactive power transmitted

$$
Q=\frac{V_{i}^{2}}{X}-\frac{V_{i^{*}} V_{s h}}{X} \cos \left(\delta_{i}-\delta_{s h}\right)
$$

Where $V_{i}, V_{s h}$ are the voltage at the nodes, $\left(\delta_{i}-\delta_{s h}\right)$ the angle between the voltage and $\mathrm{X}$ the line impedance. After performing some complex operations, the following active and reactive power equations are obtained as follows:

$$
\begin{aligned}
& P_{s h}=V_{i}^{2} g_{s h}-V_{i} V_{s h}\left(g_{s h} \cos \left(\theta_{i}-\theta_{s h}\right)+b_{s h} \cos \left(\theta_{i}-\theta_{s h}\right)\right) \\
& Q_{s h}=-V_{i}^{2} b_{s h}-V_{i} V_{s h}\left(g_{s h} \sin \left(\theta_{i}-\theta_{s h}\right)-b_{s h} \sin \left(\theta_{i}-\theta_{s h}\right)\right) \\
& \mathrm{g}_{s h}+\mathrm{jb} b_{s h}=1 / Z_{\text {sh }} \\
& \text { g g } 5 \text { : Equivalent conductance of the STATCOM. } \\
& b_{s h}: \text { Equivalent susceptance of the STATCOM. } \\
& \mathrm{Z}_{s h}: \text { Equivalent impedance of the STATCOM. }
\end{aligned}
$$

\section{Simulation and Numerical Results}

The proposed algorithm is implemented and tested on a standard IEEE 30-Bus test system; it consists of 6 generators located at buses 1, 2, 3, 5, 8, 11, and 13, 41 branches (lines) and four transformers in line 6-9, 6-10, 4-12, and 28-27. The algorithms were implemented using the Matlab programming language; detailed analyses of the results are presented and discussed in this section.
A total of three different case studies were considered, in the first case study, only to verify the effectiveness of the three PSO variant without considering the STATCOM Controllers, in case 2 the optimal reactive power is treated considering multi STATCOM and in the third case the multi objective ORPF is analysed based integration of multi STATCOM.

\section{A. Testing Strategies}

Case 1: Single objective function: Ploss and VD minimization without STATCOM Controller.

The main goal of this first case is to verify the feasibility and performance of the three proposed PSO variant to solve the ORPF problem. Table 1 shows the parameters of the three PSO variants. Figs 4-5-6 show the convergence characteristics of active power loss for the three PSO variants. Table. 2 gives the minimum, maximum, and average optimal solution over 10 trials for different algorithms. It can be seen that the minimum cost as well as average Ploss produced by the third variant named PSO3 is better compared to the two other variants, emphasizing the better solution quality of the method.

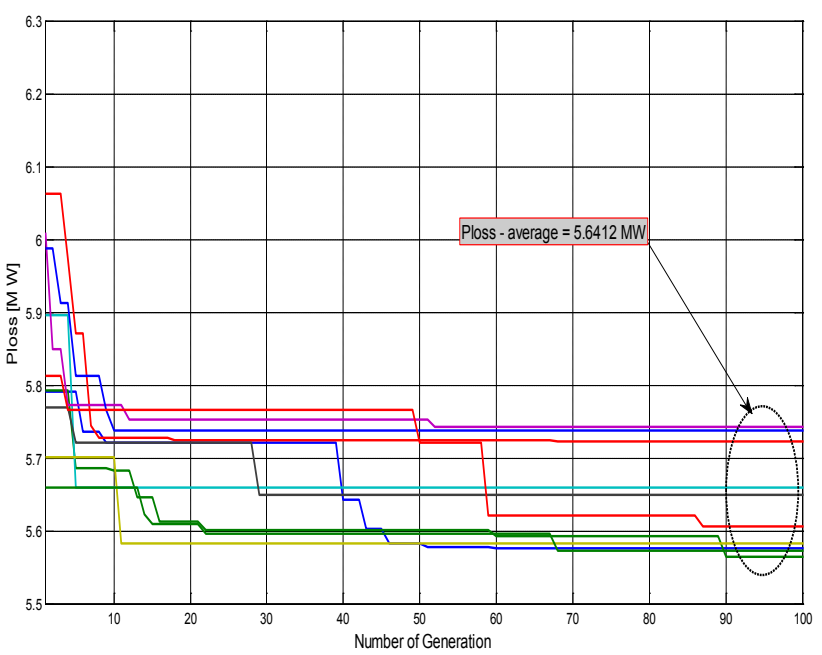

Figure 4. Convergence characteristic of active power loss using PSO1

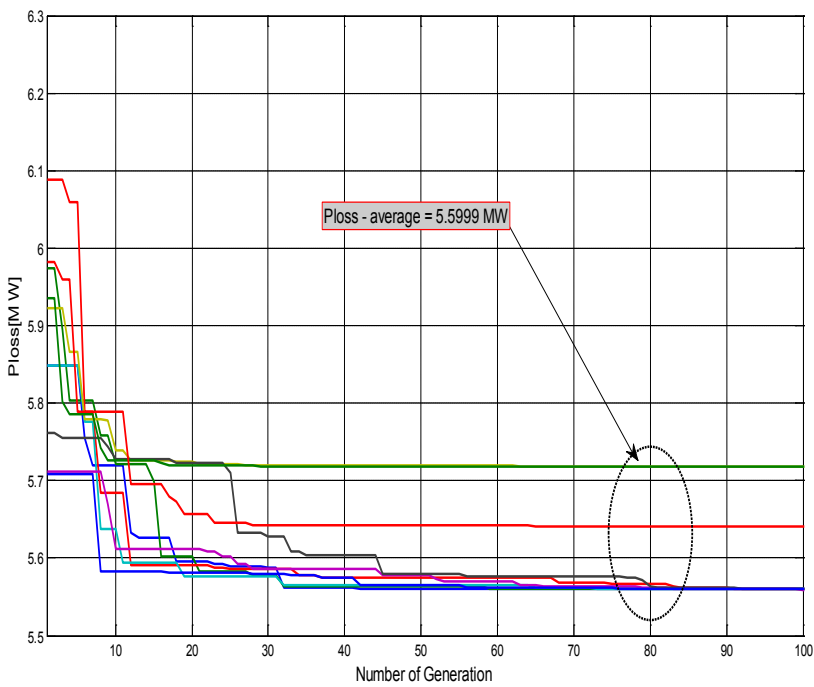

Figure 5. Convergence characteristic of active power loss using PSO2 


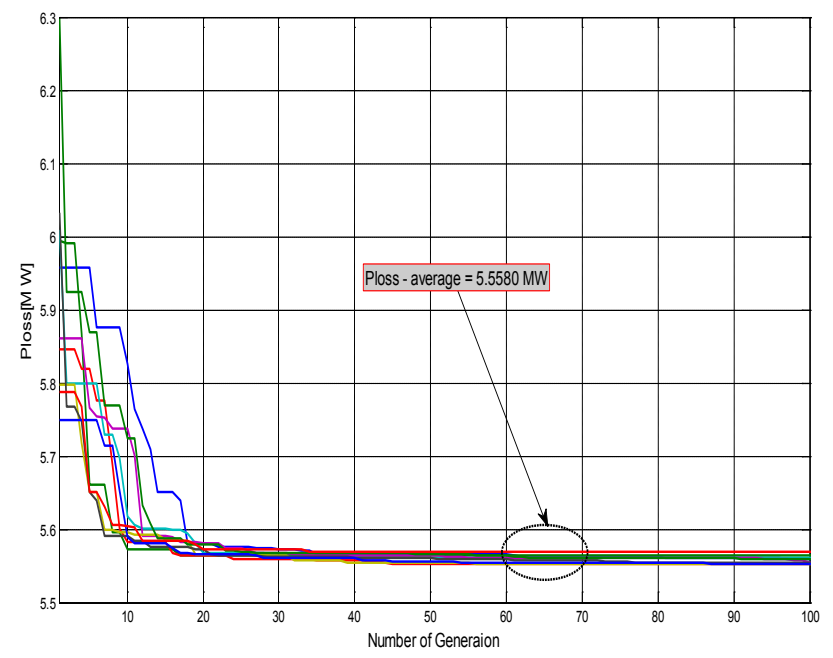

Figure 6. Convergence characteristic of active power loss using PSO3

Table 2. Simulation Result based three PSO variant.

\begin{tabular}{|c|c|c|c|}
\hline \multirow{2}{*}{} & \multicolumn{3}{|c|}{ The variant of PSO algorithm } \\
\cline { 2 - 4 } & PSO1 & PSO2 & PSO3 \\
\hline Iteration of convergence & $80-100$ & $60-80$ & $30-40$ \\
\hline Time (sec) & 39.440 & 37.170 & 36.180 \\
\hline Ploss-Max & 5.7370 & 5.7188 & 5.5700 \\
\hline Ploss- average & 5.6412 & 5.5999 & 0.5580 \\
\hline Ploss-min & 5.5645 & 5.5595 & 5.5518 \\
\hline
\end{tabular}

Effect of number of generation

Table 3. Number of generation and execution time

\begin{tabular}{|c|c|c|c|}
\hline \multirow{2}{*}{} & \multicolumn{3}{|c|}{ The variant of PSO algorithm } \\
\cline { 2 - 4 } & PSO1 & PSO2 & PSO3 \\
\hline Number of generation & 100 & 70 & 50 \\
\hline Time ( sec) & 39.44 & 25.75 & 18.29 \\
\hline Iteration of convergence & 90 & 69 & 49 \\
\hline Ploss (MW) & 5.5645 & 5.5589 & 5.5539 \\
\hline
\end{tabular}

The results from Fig 6 and Table. 3 indicate clearly that the optimal solution (best) determined by PSO3 is more advanced than that found by other method mentioned. The simulation results confirm that PSO3 is well capable of searching global or near global optimum solution. Besides, which proves $\mathrm{PSO} 3$ has a stable consistency and a refined convergence precision. In addition, the average global optimum solutions (Mean) result in lower average active power losses attained by PSO3, which is an evidence for the reliability of PSO3 with high quality solutions. Likewise, Table 3 shows the result obtained by the different number of generation. PSO3 method can converge in optimal solution when the generation achieves the maximal generation $(20$ generations) to PSO1 (100 generations) and PSO2 (50 generations). It is observed that the simulation running time is enhanced in the third variant (PSO) compared to the others variants.

Case 2: Single objective function: Ploss and VD minimization considering STATCOM Controller.

In this section the objective is to test the performance of PSO based FACTS using multi STATCOM Controllers by adjusting dynamically their parameters setting. Two objectives function are considered individually (power loss re- duction and voltage deviation). The best results of the two objective functions optimized individually are given in Table 4 for power loss and Table 5 for voltage deviation. Convergence characteristics of power loss and voltage deviation are shown in Fig 7 and Fig 8 respectively, Fig 9 shows voltage profiles at all buses, Figs 10 show the convergence characteristics of generators voltage control based PSO3.

Table 4. Power flow results with multi-STATCOM (active power losses)

\begin{tabular}{|c|c|c|c|c|}
\hline \multicolumn{2}{|c|}{} & \multicolumn{3}{|c|}{ The variant of PSO algorithm } \\
\cline { 3 - 5 } \multicolumn{2}{|c|}{} & PSO1 & PSO2 & PSO3 \\
\hline With one & $\mathrm{P}_{\text {loss }}(\mathrm{MW})$ & 5.6680 & 5.4978 & 5.4882 \\
\cline { 2 - 5 } STATCOM & $\mathrm{V}_{\mathrm{D}}$ & 1.0765 & 0.9605 & 1.0731 \\
\hline With tow & $\mathrm{P}_{\text {loss }}(\mathrm{M} \mathrm{W})$ & 5.5750 & 5.4440 & 5.1435 \\
\cline { 2 - 5 } STATCOM & $\mathrm{V}_{\mathrm{D}}$ & 1.2688 & 0.7201 & 0.9366 \\
\hline With three & $\mathrm{P}_{\text {loss }}(\mathrm{M}$ W) & 5.5253 & 5.4172 & 5.2650 \\
\cline { 2 - 5 } STATCOM & $\mathrm{V}_{\mathrm{D}}$ & 1.1696 & 1.1120 & 0.7230 \\
\hline
\end{tabular}

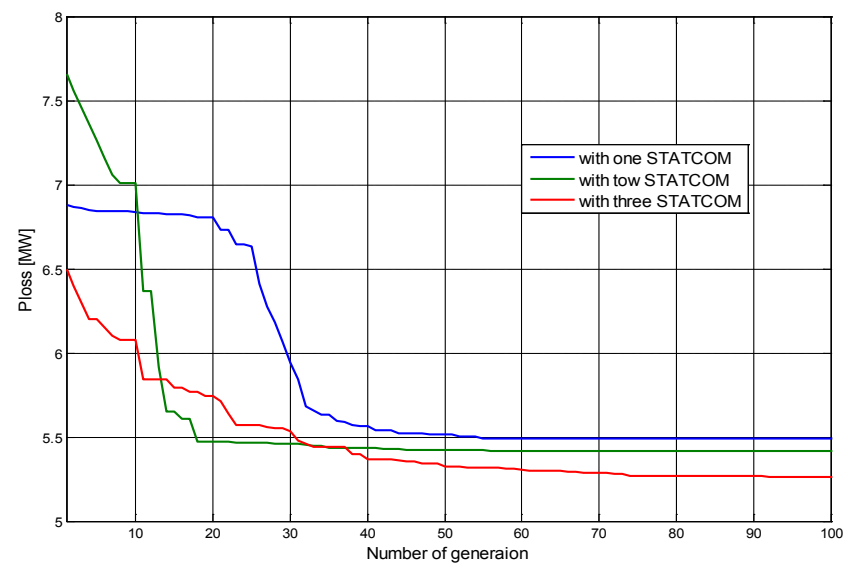

Figure 7. Convergence characteristic of active power loss with three STATCOM

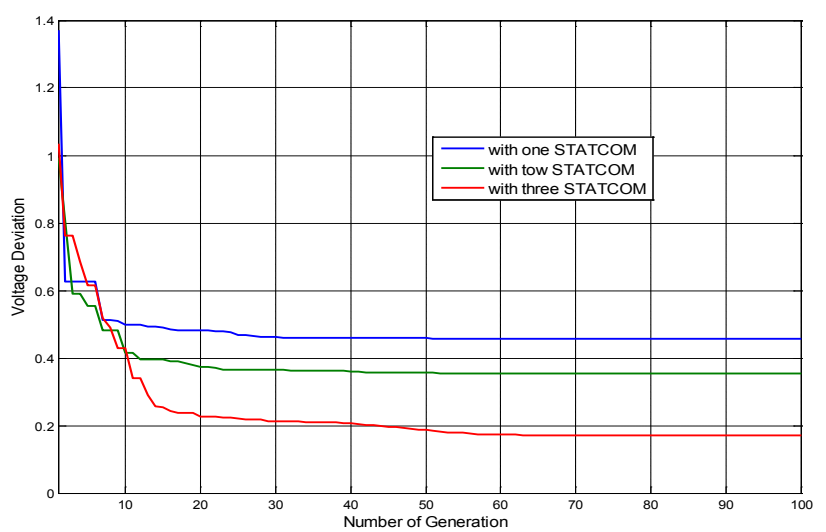

Figure 8. Convergence characteristic of voltage deviation with three STATCOM

Table 5. Best solution for voltage deviation with STATCOM

\begin{tabular}{|c|c|c|c|c|}
\hline \multicolumn{2}{|c|}{} & \multicolumn{3}{|c|}{ The variant of PSO algorithm } \\
\cline { 3 - 5 } \multicolumn{2}{|c|}{} & PSO1 & PSO2 & PSO3 \\
\hline With one & $\mathrm{V}_{\mathrm{D}}$ & 0.5533 & 0.4595 & 0.4576 \\
\cline { 2 - 5 } STATCOM & $\mathrm{P}_{\text {loss }}(\mathrm{MW})$ & 7.2199 & 7.2131 & 7.4872 \\
\hline With two & $\mathrm{V}_{\mathrm{D}}$ & 0.4703 & 0.3590 & 0.3542 \\
\cline { 2 - 5 } STATCOM & $\mathrm{P}_{\text {loss }}(\mathrm{M} \mathrm{W})$ & 6.5358 & 7.4813 & 7.0482 \\
\hline With three & $\mathrm{V}_{\mathrm{D}}$ & 0.4012 & 0.2077 & 0.1717 \\
\cline { 2 - 5 } STATCOM & $\mathrm{P}_{\text {loss }}(\mathrm{M} \mathrm{W})$ & 8.6825 & 7.9893 & 6.9881 \\
\hline
\end{tabular}




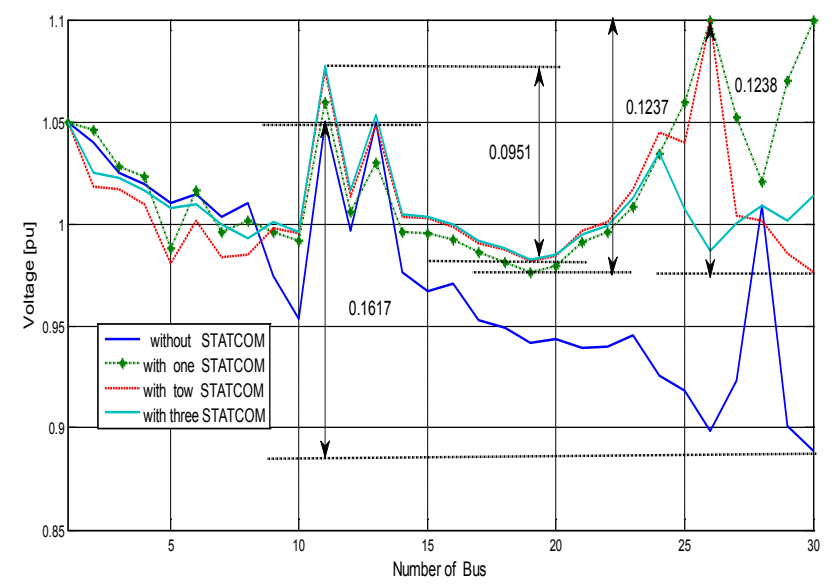

Figure 9. Voltage profiles at all buses: IEEE 30-Bus with multi STAT$\mathrm{COM}$

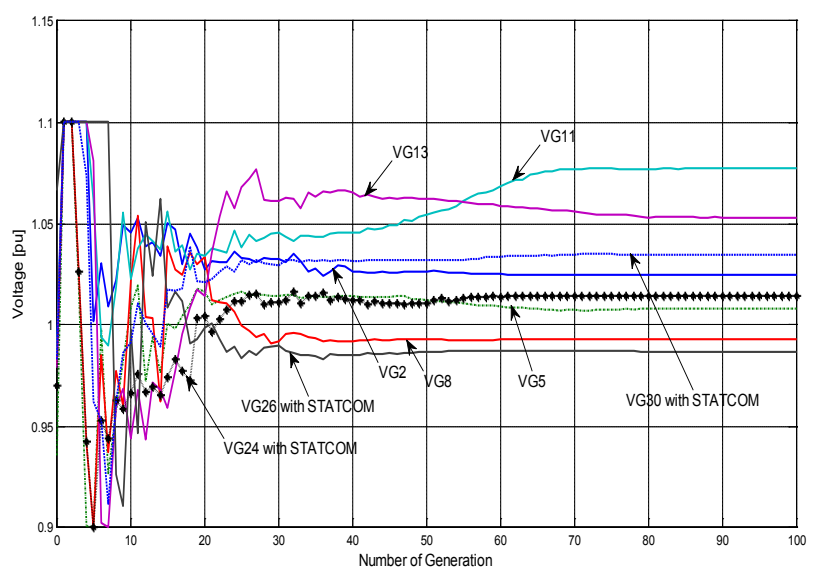

Figure 10. Convergence characteristics of generators voltage control with $\mathrm{PSO} 3$

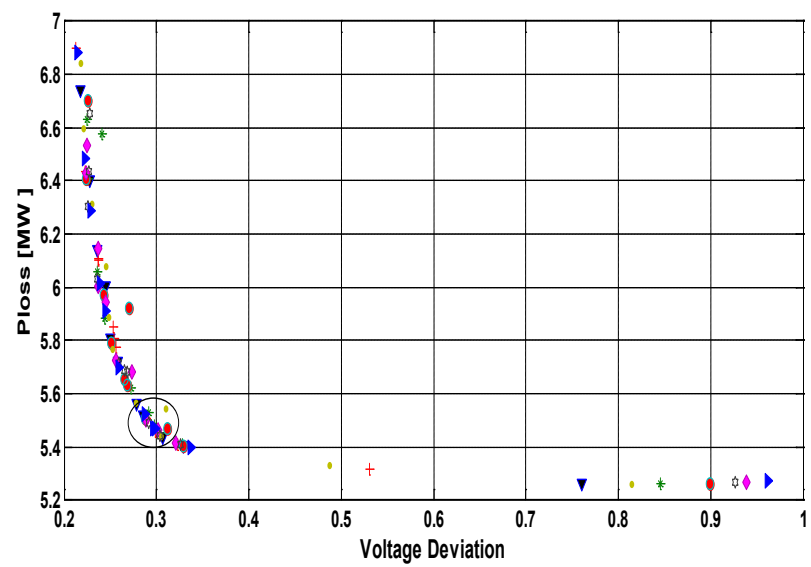

Figure 11. Pareto optimal solution results based PSO3

Case 3: Multi Objective optimization: Ploss and VD minimization with STATCOM Controller.

In order to verify the efficiency of the proposed PSO variant, voltage control of generating units and reactive power of three STATCOM installed at specified buses considered to optimize simultaneously two objective functions (voltage deviation and power losses). Fig 11 shows the Pareto optimal solution results using the third variant of PSO, the results of this variant (PSO3) show clearly that PSO3 leads to lower active power loss (5.3751 MW) and voltage deviation ( 0.3651 p.u) compared to the other PSO variant, details results will be given in the final version of the paper.

\section{Conclusions}

Multi objective optimal reactive power flow, considering multi dynamic controllers based FACTS technology is becoming one of the most important issue in power system planning and control. This paper presented the effect of the application of modified variant of PSO to adjust dynamically the voltage control of generators and the reactive power of multi STATCOM exchanged with the network considering both power loss and voltage deviation. The results demonstrated the performances of the proposed approach based PSO3 variant in term of solution quality and convergence characteristic compared to the two others variants.

\section{REFERENCES}

[1] Dai, C.,Chen, W.,Zhu, Y.; Zhang, X . "Seeker optimization algorithm for optimal reactive power dispatch,', IEEE Trans power syst. 2009, 1(2),pp. 1218-1231.

[2] Kirschen DS, Van Meeteren HP. "MW/voltage control in linear programming based optimal power flow'. IEEE Trans Power Syst 1988;3(4)pp481-489.

[3] Momoh JA, Adapa R, El-Hawary ME. 'A review of selected optimal power flow literature to 1993. I. Nonlinear and quadratic programming approaches". IEEE Trans Power Syst 1999,14(1),pp96-104.

[4] Quitana VH, santos-Nieto M. , “Reactive-power dispatch by successive quadratic programming”, IEEE Trans Energy convers 1989;4(3), pp.425-435.

[5] Momoh JA, El-Hawary ME, Adapa R. 'A review of selected optimal power flow literature to 1993. II. Newton, linear programming and interior point methods" IEEE Trans Power Syst1999, 14(1),pp.105-111.

[6] Manlovani, J.R.S., Garcia, A.V. "A heuristic method for reactive power planning,", IEEE Trans Power Syst 1995;11(1),pp.68-74.

[7] Liu K., Sheng W., and Y.Li. "research on reactive power optimization based on immunity genetic algorithm,", Springer, ICIC 2006, LNCS 4113, 2006,pp.600-611.

[8] Yoshida H, Fukuyama Y, Kawata K, Takayama S, Nakanishi Y. "A particle swarm optimization for reactive power and voltage control considering voltage security assessment," IEEE Trans Power Syst 2001,15(4),pp1232-1239.

[9] Wang, H.,Xiong, X., Wu, Y, '’.power system reactive power optimization based on modified tabu search algorithm ',power system technology 2002. 1,pp15-18

[10] Zhang X, Chen W, Dai C, Cai W. "Dynamic multi-group self-adaptive differential evolution algorithm for reactive power optimization', Elect Power and energy syst, 2010, 32,pp.351-357. 
[11] Varadarajan M, Swarup KS. "Network loss minimization with voltage security using differential evolution', Elect Power Sys 2008, 78(5), pp.815-823.

[12] Kennedy J, Eberhart R., "Particle swarm optimization" In: Proceedings of the IEEE conference on neural networks (ICNN'95), vol. IV. Perth, Australia; 1995. pp.1942-1948.

[13] N.G. Hingorani, L. Gyugyi, 'Understanding FACTS Concepts and Technology of Flexible AC Transmission Systems', IEEE Press, New York, 2000.

[14] B. Mahdad, "Differential evolution based dynamic decomposed strategy for solution of large practical economic dispatch", EEEIC 10th International Conference on Environment and Electrical Engineering, Italy, 2011.

[15] X.P. Zhang, E Handschin, M Yao. 'Multi-control functional static synchronous compensator (STATCOM) in power system steady-state operations', Elect Power Syst Res, 2004, 72, pp 269-278.

[16] B. Mahdad "Contribution to the improvement of power quality using multi hybrid model based Wind-Shunt FACTS," 10th EEEIC International Conference on Environment and Electrical Engineering, Italy, 2011.

[17] P. L. So, Y. C. Chu, T. Yu, "Coordinated control of TCSC and SVC for system damping enhancement", International Journal of Control, Automation, and Systems, June 2005Vol. 3, No. 2, pp 322-33,

[18] M.A. Abido. "A novel multiobjective evolutionary algorithm for environmental/economic power dispatch" Elect Power Syst Res, 2003, 65,pp 71-81.

[19] D.W. Gong, Y Zhang, C.L Qi. "Environmental/economic power dispatch using a hybrid multi-objective optimization algorithm'. Elect Power and energy syst, $2010,32, p p, 607-614$.

[20] Shi Y, Eberhart RC. "Empirical study of particle swarm optimization”. Proc IEEE Int Congr Evol Comput 1999,(3), pp101-106.

[21] Eberhart RC, Shi Y. 'Comparing inertia weights and constriction factors in particle swarm optimization". Proc Congr Evol Comput 2000;1,pp 84-88 